\title{
The Quality of Pellets Available on the Market in Latvia: Classification According EN 14961 Requirements
}

\author{
Vladimirs Kirsanovs ${ }^{1}$, Lelde Timma ${ }^{2}$, Aivars Zandeckis ${ }^{3}$, Francesco Romagnoli ${ }^{4},{ }^{1-4}$ Institute of Energy Systems and \\ Environment, Riga Technical University
}

\begin{abstract}
The objectives of the paper are to determine the quality of pellets available on the market in Latvia and to compare results with the European standard EN 14961-2:2011. The following parameters have been determined for samples of pellets: length, diameter, moisture and ash content, mechanical durability, lower calorific value and bulk density. The results showed that all samples confirm to the $B$ class requirements of the standard. If one considers the A1 class - only 4 out of 9 samples fit the requirements. The paper emphasizes the need for the introduction of a quality control system for the wood pellets market in Latvia.
\end{abstract}

Keywords - biomass pellets, pellet quality

\section{INTRODUCTION}

The production of wood pellets started in the second half of the 1970s in North America. Nowadays wood pellets are produced in significant volumes in Europe and other parts of the world. Wood pellets have the important role of replacing fossil fuels in the European Union (EU) market. The production of wood pellets has been increasing substantially [1]. In Latvia, the consumption of wood pellets increased up to 2.4 times from $234 \mathrm{TJ}$ in 2009 up to $562 \mathrm{TJ}$ in 2010 [2].

Since wood resources are limited and can be used in other processes as well, a lot of attention is paid to testing pellets, which are produced from various non-woody types of biomass. Studies by Filbakk et al. [3] show that pellets with elevated bark share have a relatively higher bulk density and a lower amount of fines, but at the same time the ash content increases as well. In the research pellets with a bark fraction from $10 \%$ up to $100 \%$ were examined. Work done by Verma et al. [4] describes combustion efficiency and an emissions rate from various types of pellets. In the paper pellets produced from wood, apple, peat, reed canary grass, sunflower husk and citrus pectin waste were considered.

In order to regulate the quality of pellets available on the market, some EU countries have been developing standards for quality benchmarking of produced biomass fuel. The normative requirements for the pellets differ from standard to standard. The standards also regulate a diverge modes of pellets' applications. García-Maraver presents a comparative study of regulations and standards created by government authorities in different countries [5].

The introduction of quality benchmarking is an important factor for ensuring an effective combustion process. The investigation regarding the emission characteristics of modern and old-type residential boilers with wood and wood pellets was carried out by Johansson et al. [6]. They concluded that the low quality of fuel can be the cause of high emissions from modern boilers.

A range of physical, chemical and mechanical properties of wood pellets have an impact on the quality of biomass fuel. In particular, the influence of bulk density, moisture, ash, fines content and net calorific value on the efficiency and emission rates in biomass energy systems is proven in work done by Johansson et al. [6]. The work done by Ståhl et al. [7] states that efficiency of the combustion process is decreasing than fuel with high ash content is used. Research done by Samuelsson et al. [8] points out another important factor to consider: the moisture content in the raw biomass, which influences the bulk density and net calorific value of the final product. The mean diameter and mean length of the pellets should be considered as well, because standardized pellet feeding technologies are on the market in the EU [4]. Research done by Dias et al. [9] shows that pellets with a larger diameter have a lower boiler efficiency and pellets with lower mechanical durability contain more fines. Work done by Ståhl et al. [7] defines the influence of bulk density on the boiler efficiency. Bulk density is affecting mass of fuel feed into the burner and the amount of air needed for combustion. In boilers without automatic control systems, changes in bulk density can affect behaviour of the combustion process and increase heat losses. Mechanical durability, the amount of fines and bulk density are factors important in maintaining a good quality of pellets during the transportation process. Work done by Filbakk et al. [3] states that a large concentration of fines can create problems with proper pellet combustion and efficiency decreasea as a result. It can be concluded, that there are a set of parameters which are essential for proper combustion process.

The government regulation can force producers to improve the quality of biomass fuel. Work done by Ståhl et al. [7] shows, that stricter regulations have improved the quality of pellets available on the market in Sweden. Nonetheless, the biggest problems are caused by low mechanical durability because regulations concerning this parameter are not so strict.

A paper presented by Park [10] describes, that the most important problems occur with the crumbling of pellets, which is caused by low mechanical durability. The ash content generally can vary in a wide range from $0.5 \%$ up to $2.7 \%$.

The objectives of the paper are to find out the quality of the pellets available on the market in Latvia and to compare these 
results with the European standard LVS EN 14961-2:2011 Solid Biofuel - Fuel specification and classes. Part 2: Wood pellets for non-industrial use [11]. The physical properties of the pellets are stated according to the Technical Specifications of the European Commission for Standardization (CEN/TS) methodology.

\section{METHODS AND MATERIALS}

The pellet samples were gathered from various regions of Latvia. In total nine pellet samples from woody biomass were analysed. The physical parameters for the pellets were determined according to the methods described in the CEN/TS. The tested parameters and the precision for each method are given in Table I.

According to the LVS EN 14961-2:2011 standard [11], wood pellets for non-industrial are divided into three classes: A1, A2 and B class. A1 class includes wood pellets which are produced from stemwood and chemically untreated wood residues. A2 class includes wood pellets produced from whole trees without roots, stemwood, logging residues, bark (from industry operations) and chemically untreated wood residues. B class includes wood pellets produced from forest, plantation and other virgin wood, by-products and residues from wood processing industry and used wood.

A1, A2 and B class have different normative for each pellet parameters. No information was available about a type of wood used for production of the tested samples. Therefore it was decided to determine how many samples would meet the requirements of each class and how many samples would not fit under any class.

TABLE I

CEN/TS METHODS FOR DETERMINATION OF THE PHYSICAL PARAMETERS FOR SOLID BIOFUELS

\begin{tabular}{|c|c|c|}
\hline Parameter & Method & Repeatability limit \\
\hline Ash content $(A), \mathrm{w}-\%, \mathrm{~d}$ & $\begin{array}{c}\text { CEN/TS } 14775 \\
{[12]}\end{array}$ & $\begin{array}{c}<2 \% \text { of the mean result } \\
(A \geq 10 \%) \\
<0.2 \% \text { absolute }(A<10 \%)\end{array}$ \\
\hline Moisture content, w- $\%$ & $\begin{array}{l}\text { CEN/TS 14774- } \\
\quad 3 \text { [13] }\end{array}$ & $<0.2 \%$ absolute \\
\hline $\begin{array}{c}\text { Net calorific value, } \\
\mathrm{MJ} \cdot \mathrm{kg}^{-1}\end{array}$ & $\begin{array}{c}\text { CEN/TS } 14918 \\
{[14]}\end{array}$ & $<120 \mathrm{~J} \mathrm{~g}^{-1}$ \\
\hline Durability $(D U)$, w-\% & $\begin{array}{l}\text { CEN/TS 15210- } \\
1[15]\end{array}$ & $\begin{array}{c}<0.4 \% \text { absolute }(D U \geq 97.5 \\
\%) \\
<2 \% \text { absolute }(D U<97.5 \\
\%)\end{array}$ \\
\hline Mean diameter, $\mathrm{mm}$ & --- & --- \\
\hline Mean length, $\mathrm{mm}$ & --- & --- \\
\hline $\begin{array}{l}\text { Bulk density }(B D), \\
\mathrm{kg} \cdot \mathrm{m}^{-3}\end{array}$ & $\begin{array}{c}\text { LVS EN } 15103 \\
{[16]}\end{array}$ & $\begin{array}{l}<4 \%\left(B D \geq 300 \mathrm{~kg} \mathrm{~m}^{-3}\right) \\
<6 \%\left(B D<300 \mathrm{~kg} \mathrm{~m}^{-3}\right)\end{array}$ \\
\hline
\end{tabular}

\section{RESULTS}

Based on the CEN/TS methodology, the physical parameters of the pellets were obtained, the results of which are presented in Table II. The first five samples are from resellers, but others are from producers. The results presented in Table II differ in a wide range, therefore there are pellets which do not satisfy the requirement of LVS EN 14961:22011 standard [11].

\section{A. Requirements for pellets' mean diameter}

Based on the LVS EN 14961:2-2011 standard [11] requirements, according to the sample diameter - all pellets are divided into two groups: pellets with diameter $6 \pm 1 \mathrm{~mm}$ and pellets with diameter $8 \pm 1 \mathrm{~mm}$. The designations for the groups are: D06 and D08. All classes A1, A2 and B have the same requirements - either D06 or D08. Therefore based on the standard, the diameters for the pellets can vary in a range from $5 \mathrm{~mm}$ to $9 \mathrm{~mm}$, see Figure 1 .

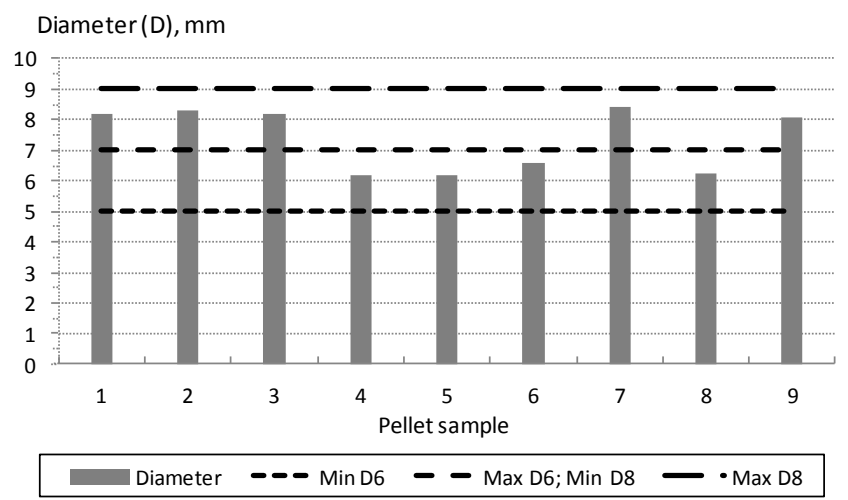

Fig. 1. The diameter for tested samples

The results show that all pellet samples meet the standard requirements, see Figure 1. Four pellet samples meet the requirements of group D06 and the other five -- group D08.

The diameter of pellets have a crucial role for the combustion process in the pellet boiler. The boilers with internal pellet storage are a common technical solution in Latvia. Usually, a screw-type transporter is used for feeding the pellets from internal storage to the burner [20]. Screw conveyors have standardized sizes and therefore the diameter of the pellets must be standardized as well otherwise the operation of the boiler can be disrupted. Most of screw-type conveyors produced in EU are designed to operate with $6 \mathrm{~mm}$ and $8 \mathrm{~mm}$ pellets [1].

\section{B. Requirements for pellets' mean length}

According to the LVS EN 14961:2-2011 standard [11] pellets are not divided in separate groups by length. The requirements for length only state an upper limit $(40 \mathrm{~mm})$ and lower limit $(3.15 \mathrm{~mm})$. Since the range for normative length is so wide, all pellet samples confirm standard requirements. Based on the research of Beloborodko et al. [17], mean diameter strongly affects the amount of fines. A smaller mean diameter of pellets leads to a higher amount of fines. Large concentrations of the fines can create problems during the combustion process in the burner and, as a result, there is an overall decrease of boiler efficiency [5]. It can be concluded, that pellets with standardized mean length and diameter are advisable for small scale use. 
TABLE II

PHYSICAL PARAMETERS OF THE TESTED WOOD PELLETS

\begin{tabular}{|c|c|c|c|c|c|c|c|}
\hline \multirow{3}{*}{ Sample } & \multicolumn{7}{|c|}{ Parameter } \\
\cline { 2 - 8 } & $\begin{array}{c}\text { Ash } \\
\text { content, } \\
\text { w-\%, d }\end{array}$ & $\begin{array}{c}\text { Moisture } \\
\text { content, } \\
\text { w-\% }\end{array}$ & $\begin{array}{c}\text { Net calorific } \\
\text { value, } \\
\text { MJ.kg }\end{array}$ & $\begin{array}{c}\text { Durability, } \\
\text { w-\% }\end{array}$ & $\begin{array}{c}\text { Mean } \\
\text { diameter, } \\
\text { mm }\end{array}$ & $\begin{array}{c}\text { Mean } \\
\text { length, } \\
\mathrm{mm}\end{array}$ & $\begin{array}{c}\text { Bulk density, } \\
\mathrm{kg} \cdot \mathrm{m}^{-3}\end{array}$ \\
\hline 1 & 1.2 & 6.1 & 17.87 & 97.7 & 8.20 & 13.37 & 660 \\
2 & 0.8 & 7.1 & 17.70 & 97.5 & 8.28 & 19.96 & 670 \\
3 & 0.7 & 4.4 & 18.33 & 96.0 & 8.21 & 18.20 & 720 \\
4 & 0.7 & 6.7 & 17.61 & 98.7 & 6.17 & 21.15 & 700 \\
5 & 0.4 & 4.0 & 18.38 & 97.5 & 6.19 & 14.64 & 720 \\
6 & 0.4 & 8.1 & 17.58 & 92.6 & 6.60 & 12.86 & 590 \\
7 & 0.5 & 6.9 & 17.44 & 97.7 & 8.42 & 14.47 & 680 \\
8 & 2.4 & 8.2 & 16.61 & 94.4 & 6.27 & 8.71 & 660 \\
9 & 0.6 & 7.5 & 18.00 & 97.8 & 8.08 & 11.20 & 700 \\
\hline
\end{tabular}

${ }^{*} \mathrm{w}-\%$, d weight-percentage, dry basis

${ }^{* * *}$ w- $\%$ weight-percentage

\section{Requirements for pellets' mechanical durability}

The mechanical durability of the pellet must be more than $97.5 \%$ for A1 and A2 class and $96.5 \%$ for B class. The results are presented in Figure 2.

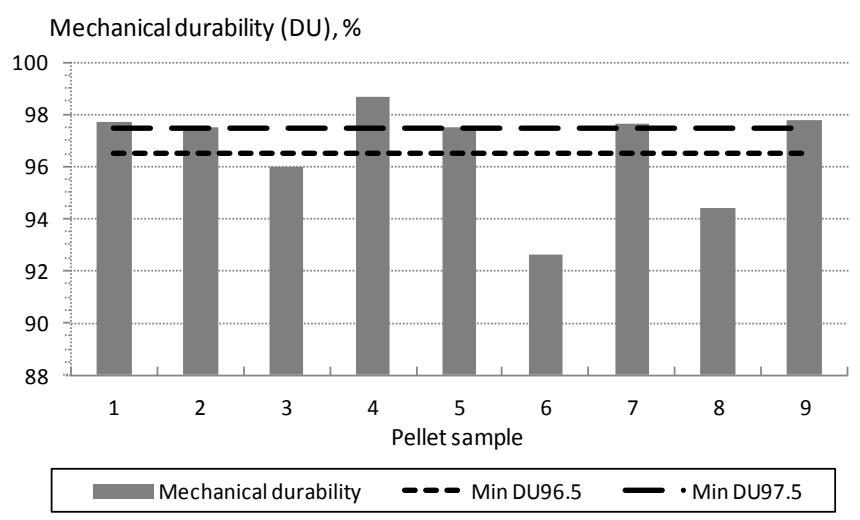

Fig. 2. Mechanical durability for tested samples

Six samples of tested pellets fit the standard requirement according to the $\mathrm{A} 1$ and $\mathrm{A} 2$ classes. The remaining three samples do not fit any of the A1, A2 or B class requirements. The pellets with higher mechanical durability are better fit for combustion in the boiler, due to the lesser amount of fine present in the combustion process [9].

High mechanical durability is a precondition for the pellets to maintain good quality during transportation [3].

\section{Requirements for pellets' bulk density}

All pellet classes have the same normative for bulk density. Bulk density for the pellet must be at least $600 \mathrm{~kg} \bullet \mathrm{m}^{-3}$. There was only one sample which did not fit the requirements. Variations in the bulk density can decrease the efficiency of the boiler. If the bulk density is higher, then more fuel is fed into the burner. At the same time, more air is needed for the combustion process. If regulation of the boiler is not adjusted for bulk density variations, the efficiency of the boiler will decrease as a result [7].

\section{E. Requirements for pellets' moisture content}

A1, A2 and B classes have the same requirement for moisture content in wood pellets. A moisture content of the pellets must be less than $10 \%$ by mass according to the LVS EN 14961:2-2011 standard [11]. All tested samples fit the standard requirements for the moisture content.

Work done by Samuelsson et al. [8] shows that moisture content significantly influences net calorific value and bulk density for biomass fuels. Since net calorific value is a function of moisture content, wood pellets with comparable chemical composition, but lower moisture content will have higher net calorific value. For consumers in Latvia it is beneficial, that the moisture content for all nine pellet samples is smaller than $10 \%$. Lower moisture content means - less surplus energy is spent in the burner for water evaporation from pellets.

\section{F. $\quad$ Requirements for pellets' ash content}

The upper value for ash content in wood pellets is different for each pellets' class according to the LVS EN 14961:2-2011 standard [11]. According to the A1 class normative ash content must be lower than $0.7 \%$ of the total pellet mass. For A2 class, the ash content must be lower than $1.5 \%$. The B class pellet can contain ash content nomore than $3.0 \%$, which is the highest permitted value in the standard. The results on ash content are given in Figure 3.

Six pellet samples have ash content less than $0.7 \%$ and fit the A1 class normative, which corresponds to a high quality biomass fuel. Only one sample shows a relatively higher ash content and therefore only fits the B class requirements.

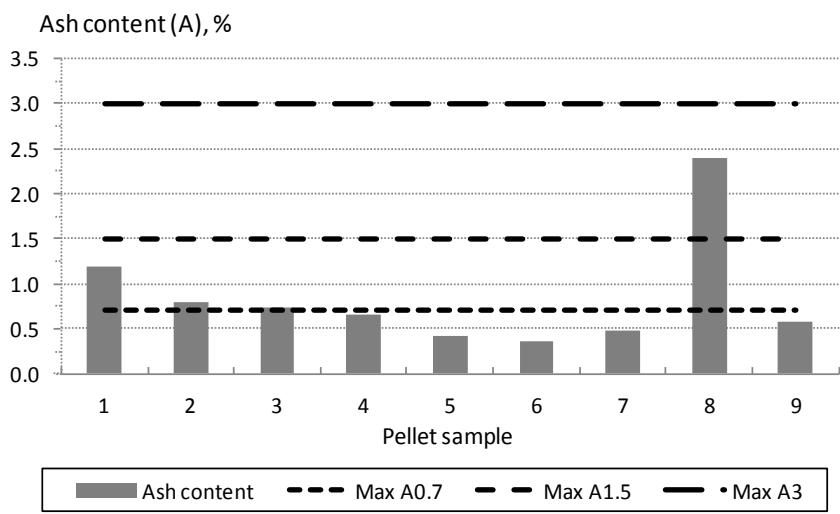

Fig. 3. Ash content for tested samples 
Ash content requirements are an important factor for an appropriate combustion process. Work done by Ståhl et al. [7] shows, that boiler efficiency decreases under the conditions of high ash amount since increased amount of unburned material is present in the burner and on the heat exchange surfaces.

Since ash accumulates on the boiler internal surfaces, pellets with smaller ash content are also better from the boiler maintenance point of view because the boiler operator does not need to clean the boiler as often.

\section{G. Requirements for pellets' net calorific value}

The net calorific value must be at least $16.5 \mathrm{MJ} \bullet \mathrm{kg}-1$ for A1 class pellets according to the LVS EN 14961:2-2011 standard [11], $16.3 \mathrm{MJ} \cdot \mathrm{kg}-1$ for A2 class. The B class pellets have the lowest requirements: at least $16.0 \mathrm{MJ} \cdot \mathrm{kg}-1$. The results about net calorific value for tested pellets are given in Figure 4.

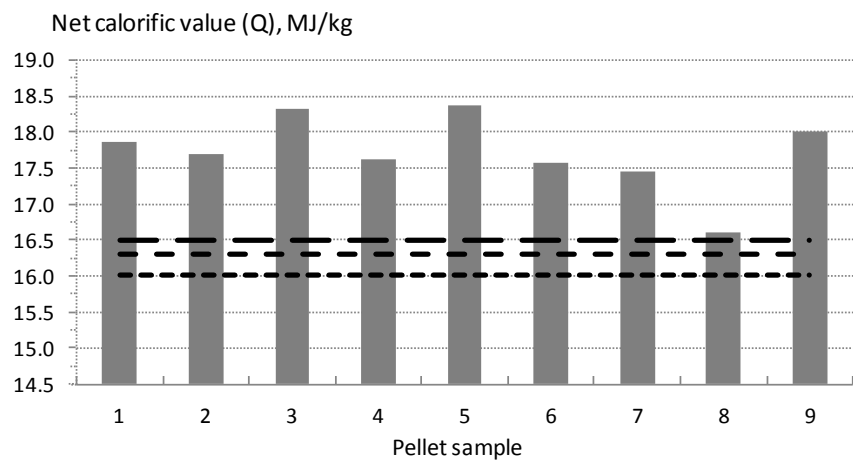

Net calorific value $-\bullet \operatorname{Min}$ Q16.5 - - Min Q16.3 - - Min Q16.0

Fig. 4. Net calorific value for the tested samples

The result shows that all pellet samples fit the standard minimal requirements for A1 class. The net calorific value shows how much heat energy can be produced by the pellet boiler. In fact, the net calorific value is a function of moisture content, ash content and chemical composition of fuel, but net calorific value cannot be used as the only control parameter. A good example is the sample 8: the pellets met the minimal standard requirement on net calorific value and moisture content satisfactorily, so it would also seem a satisfactory quality biomass fuel, but at the same time ash content fits only $\mathrm{B}$ class regulations. In this particular case, boiler efficiency would decrease rapidly and the boiler operator would need to invest more work in operating the boiler in order to keep its internal surfaces clean from ashes. This example shows the need for all aforementioned regulations, since it is not enough to state only a couple of requirements.

\section{CONCLUSIONS}

In total nine pellet samples were analysed. The samples were gathered from various places in Latvia. All pellet samples were produced from woody biomass.

The results show that all pellets samples met the standard requirements for mean diameter, mean length, moisture content and net calorific value.

The largest difficulties for tested samples were to match ash content and mechanical durability requirements stated in the
LVS EN 14961:2-2011 standard [11]. Six out of nine samples could satisfy A1 class requirements on ash content; eight out of nine satisfy $\mathrm{A} 2$ class requirements and nine out of nine $-\mathrm{B}$ class requirements. The elevated ash content could be explained by the weak process control of pellet manufacturing and/or poor quality of raw materials. Mechanical durability was not sufficient for three out of nine samples.

Based on the origin of the biomass, the standard LVS EN 14961:2-2011 [11] defines different requirements for three categories (A1, A2 and B). It could not be stated what kind of wood was used in the production of each tested sample of pellet. Therefore it was decided to determine how many samples would meet the requirements of each class and how many samples would not fit under any class.

If the tested pellet samples were produced from forests, plantations, virgin wood, by-products and residues from wood processing industry or used wood (B class accordingly to LVS EN 14961:2-2011 standard [11]), then six out of nine samples would confirm B class requirements. B class requirements are the lowest defined in the standard and there are still wood pellet samples which do not satisfy these requirements. All samples met the requirements for ash content, but mechanical durability and low bulk density was too low.

If the tested pellet samples were produced from whole trees without roots, stemwood, logging residues, bark (from industry operations) or chemically untreated wood residues (A2 class accordingly to LVS EN 14961:2-2011 standard [11]), then six out of nine would conform to the standard normative.

If the tested pellet samples were produced from stemwood, chemically untreated wood residues (A1 class accordingly to LVS EN 14961:2-2011 standard [11]), then only four samples out of nine would meet all standard requirements. Since A1 class has stricter regulations on ash content, there were samples which did not meet the ash content requirements.

It can be concluded wood pellets of various qualities that fit under the A1 class and some only the lowest B class requirements are available on the market in Latvia. Since there are no regulations in the wood pellet market in Latvia, a customer cannot compare various types of pellets available on the market. Therefore there is a need for quality control of the wood pellets market in Latvia. In order to ensure a qualitative use and competitive production of wood fuel in Latvia, the participation of the local government is needed. The implementation of a strict and detailed legislation, which introduces similar requirements for produced wood pellets as the European standard LVS EN 14961-2:2011 can improve the quality of the pellets available on the market.

\section{ACKNOWLEDGEMENT}

This work has been supported by the European Social Fund within the project «Support for the implementation of doctoral studies at Riga Technical University». The work was supported by the European Economic Area Financial Mechanism, Programme "Environmental policy and integration of Latvia " and by the European Regional Development Fund from European Commission within the framework of "CentralBaltic INTERREG IV Programme 
2007-2013" for the implementation of the project "Energy Efficient and Ecological Housing" (ECOHOUSING).

The authors also express special acknowledgement to laboratory assistant Ms. Anna Beloborodko for her work on wood pellet testing.

\section{REFERENCES}

1. Vinterbäck J. Pellets 2002: the first world conference on pellets. Biomass and Bioenergy, N 27, p. 513-520.

2. Energy statistics 2010. Central Statistical Bureau of Latvia. Riga, Latvia; 2011.

3. Filbakk T., Jirjis R., Nurmi J., Høibø O. The effect of bark content on quality parameters of Scots pine (Pinus sylvestris L.) pellets. Biomass and Bioenergy, 2011, N 35, p. 3342-3349.

4. Verma V.K., Bram S., Delattin F., Laha P., Vandendael I., Hubin A., De Ruyck J. Agro-pellets for domestic heating boilers: Standard laboratory and real life performance. Applied Energy, 2012, N 90, p. 1723.

5. García-Maraver A., Popov V., Zamorano M. A review of European standards for pellet quality. Renewable Energy, 2011, N 36, p. $3537-$ 3540 .

6. Johanssona L., Lecknerb B., Gustavssona L., Cooperc D., Tullina C., Potterc A. Emission characteristics of modern and old-type residential boilers fired with wood logs and wood pellets. Atmospheric Environment, 2004, N 38, p. 4183-4195.

7. Ståhl M., Wikström F. Swedish perspective on wood fuel pellets for household heating: A modified standard for pellets could reduce enduser problems. Biomass and Bioenergy, 2009, N 33, p. 803-809.

8. Samuelsson R., Thyrel M., Sjöström M., Lestander T. A. Effect of biomaterial characteristics on pelletizing properties and biofuel pellet quality. Fuel Processing Technology, 2009, N 90, p. 1129-1134.

9. Dias J., Costa M., Azevedo J.L.T. Test of a small domestic boiler using different pellets. Biomass and Bioenergy, 2004, N 27, p. 531-539.

10. Park N. D., Rutherford P. M., Thring R. W., Helle S. S. Wood pellet fly ash and bottom ash as an effective liming agent and nutrient source for rye grass (Lolium perenne L.) and oats (Avena sativa). Chemosphere, 2012, N 86, p. 427-432.

11. EN 14961-2:2011 Solid Biofuel - Fuel specification and classes. Part 2: Wood pellets for non industrial use requirements.

12. EN 14775:2009 "Solid biofuels - Determination of ash content".

13. EN 14774-3:2009 "Solid biofuels - Determination of moisture content Oven dry method - Part 3: Moisture in general analysis sample".

14. EN 14918:2009 "Solid biofuels - Determination of calorific value".

15. EN 15210-1:2009 "Solid biofuels - Determination of mechanical durability of pellets and briquettes - Part 1: Pellets".

16. LVS EN 15103:2010 "Solid biofuels - Determination of bulk density".

17. Beloborodko A., Timma L., Žandeckis A., Romagnoli F. The regression model for the evaluation of the quality parameters for pellets. International scientific conference "Biosystems Engineering", Tartu, Estonia, May 10-11, 2012, Submitted for publication in the proceedings.

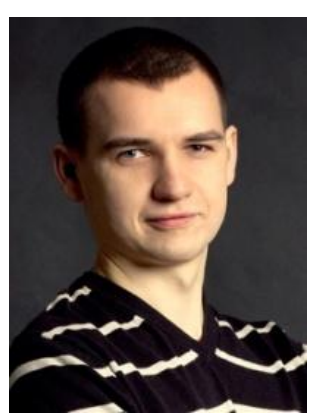

Vladimirs Kirsanovs, B.sc, Master student, assistant in scientific work at the Institute of Energy Systems and Environment of the Riga Technical University. In 2010 Vladimirs Kirsanovs acquired Bachelors degree in Environmental science at Daugavpils University. Bachelor's thesis "Change of a hydrogical regime and channel processes caused by operation of small hydro-power station in the middle stretch of the river Dubna". Now the main research areas are boiler and stove testing, combustion process optimization, efficiency advancement and emission decreasing.

Address: Kronvalda boulv. 1-022, LV-1010, Riga, Latvia

Phone: +371 67089908

E-mail: vladimirs.kirsanovs@rtu.lv

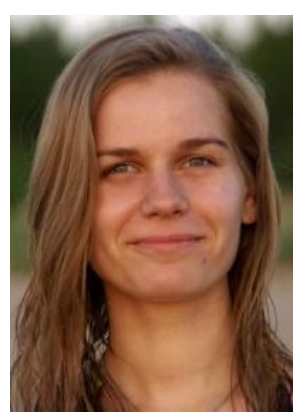

Lelde Timma, B.sc, Master student, assistant in scientific work at the Institute of Energy Systems and Environment of the Riga Technical University. In 2011 Lelde Timma acquired Bachelor degree in Environmental Engineering with work "Comparison of Solar Energy Potential in Latvia and Sweden". Main study field is renewable energy technologies and in particular solar combisystems. She has participated in two international scientific projects and is author of seven international scientific papers and two abstracts.

E-mail: lelde.timma@rtu.lv

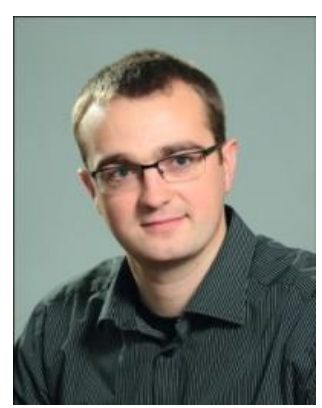

Aivars Zandeckis, M. sc., PhD student, researcher at the Institute of Energy Systems and Environment of the Riga Technical University. Since 2005 Aivars Žandeckis is working in Riga Technical University as the head of the Environmental monitoring laboratory and since 2010 as a researcher in Institute of Energy Systems and Environment Protection. The main research areas are renewable energy resources and heating technologies. He has participated in 18 local and international scientific projects related to renewable energy use and efficiency improvement in residential, tertiary and commercial sectors. Aivars is the author of 19 scientific publications and coauthor of one monograph and two local patents. He has a Master degree in Environmental Science. His masters thesis "Research of pellet combustion efficiency" was defended in Faculty of Energy and Electronics, RTU in 2008.

E-mail: aivars.zandeckis@ @tu.lv

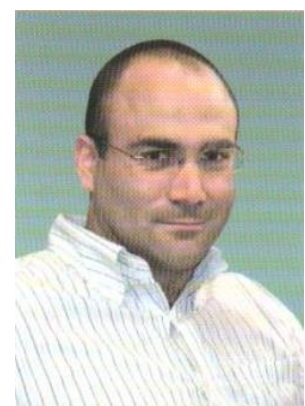

Francesco Romagnoli, $\mathrm{PhD}$, researcher at the Riga Technical University, Institute of Energy Systems and Environment. The main research field of Francesco Romagnoli is renewable energy, in particular, life cycle analysis, system dynamics and bioenergy use for heat production. $\mathrm{He}$ is the author of 33 scientific publications and takes active part in international projects. Currently he is the project coordinator for "CentralBaltic INTERREG IV Programme 20072013" for the implementation of the project "Energy Efficient and Ecological Housing" (ECOHOUSING).

E-mail: francesco.romagnoli@rtu.lv 